\title{
Soluções conservantes prolongam a vida de vaso de inflorescências cortadas de boca-de-leão
}

\author{
Preservative solution prolong the vase life of cut snapdragon inflorescences
}

\author{
Luciana Marques Vieira' ${ }^{\mathrm{I}}$ Teresa Drummond Correia Mendes ${ }^{\mathrm{II}}$ Fernando Luiz Finger ${ }^{\mathrm{III}}$ \\ José Geraldo Barbosa ${ }^{\text {III }}$
}

\section{RESUMO}

O objetivo deste trabalho foi avaliar o efeito de soluções de vaso na longevidade pós-colheita de inflorescências de bocade-leão. Hastes de boca-de-leão ('Potomac White'), colhidas com seis a sete flores abertas na inflorescência, foram condicionadas em: (1) água desionizada a $20^{\circ} \mathrm{C}$ (controle); (2) água quente a $43^{\circ} \mathrm{C}$, por uma hora, seguida de água desionizada $\left(20^{\circ} \mathrm{C}\right)$ como solução de vaso; (3) solução de Flower ${ }^{\circledR}$ a $20^{\circ} \mathrm{C}$; (4) solução de vaso preparada com $200 \mathrm{mg} \mathrm{L}^{-1}$ de $8-H Q C+20 \mathrm{~g} \mathrm{~L}^{-1}$ sacarose $+150 \mathrm{mg} \mathrm{L}^{-1}$ ácido cítrico a $20^{\circ} \mathrm{C}$; (5) água quente $\left(43^{\circ} \mathrm{C}\right)$ por uma hora e Flower ${ }^{\circledR}$ em solução de vaso $\left(20^{\circ} \mathrm{C}\right)$; e (6) água quente $\left(43^{\circ} \mathrm{C}\right)$ por uma hora $e$ solução contendo $200 \mathrm{mg} \mathrm{L}^{-1}$ de $8-\mathrm{HQC}+20 \mathrm{~g} \mathrm{~L}^{-1}$ sacarose $+150 \mathrm{mg}^{-1}$ ácido cítrico como solução de vaso $\left(20^{\circ} \mathrm{C}\right)$. A vida de vaso das inflorescências de boca-de-leão variou de três a sete dias de acordo com o tratamento utilizado. A maior longevidade foi obtida com a solução contendo 8-HQC, sacarose e ácido cítrico, tratamento que não comprometeu a abertura floral. Além disso, as inflorescências condicionadas nessa solução apresentaram ganho de massa fresca superior à massa daquelas mantidas em água desionizada ou Flower ${ }^{\circledR}$ a partir de 24 horas, atingindo 24\% de aumento no quinto dia da reidratação. Assim, o uso de soluções de vaso adequadas mantém a qualidade e prolonga a longevidade das hastes cortadas de boca-de-leão.

Palavras-chave: solução de vaso, pós-colheita, Antirrhinum majus.

\section{ABSTRACT}

The goal of this research was to evaluate the influence of vase solutions on the postharvest longevity of snapdragon inflorescences. Stems of snapdragon 'Potomac White' harvested with six to seven open flowers were treated as follow: (1) distilled water at $20^{\circ} \mathrm{C}$ (control); (2) warm water at $43^{\circ} \mathrm{C}$ for one hour, followed by distilled water $\left(20^{\circ} \mathrm{C}\right)$ as vase solution; (3) solution of Flower ${ }^{\circledR}$ at $20^{\circ} \mathrm{C}$; (4) vase solution of $200 \mathrm{mg} \mathrm{L}^{-1} 8-\mathrm{HQC}+20 \mathrm{~g} \mathrm{~L}^{-1}$ sucrose $+150 \mathrm{mg} \mathrm{L}^{-1}$ citric acid at $20^{\circ} \mathrm{C}$; (5) warm water $\left(43^{\circ} \mathrm{C}\right)$ for 1 hour followed by Flower ${ }^{\circledR}$ as vase solution $\left(20^{\circ} \mathrm{C}\right)$; (6) warm water $\left(43^{\circ} \mathrm{C}\right)$ for one hour and 200mg $\mathrm{L}^{-1} 8-\mathrm{HQC}+20 \mathrm{~g} \mathrm{~L}^{-1}$ sucrose $+150 \mathrm{mg} \mathrm{L}^{-1}$ citric acid as vase solution $\left(20^{\circ} \mathrm{C}\right)$. The vase life of snapdragon inflorescences varied from 3 to 7 days according to the treatment used. The longest longevity was obtained for the flowers treated with 8-HQC, sucrose and citric acid, which did not compromise the flower opening. Furthermore, the inflorescences kept in this solution had higher the fresh weight gain when compared to distilled water or Flower ${ }^{\circledast}$ after 24 hours, reaching $24 \%$ increase on the fifth day of rehydration. Thus, the appropriate vase solution maintains the quality and extends the longevity of cut stems of snapdragon.

Key words: vase solution, postharvest, Antirrhinum majus.

\section{INTRODUÇÃO}

As flores, assim como os vários produtos hortícolas, apresentam alta perecibilidade em razão dos processos fisiológicos catabólicos intensos. Segundo FINGER et al. (2003), após a colheita, ocorrem alterações bioquímicas, fisiológicas e estruturais que culminam com a senescência dos órgãos, sendo, portanto, processo de natureza irreversível. Dependendo da espécie, a senescência é visualmente percebida pela murcha ou pela alteração na coloração das pétalas e sépalas e, em outras, é caracterizada pela abscisão (VAN DOORN \& WOLTERING 2008).

IDepartamento de Biologia Vegetal, Universidade Federal de Viçosa (UFV), 36570-000, Viçosa, MG, Brasil. E-mail: lcsmarques@yahoo.com.br. Autor para correspondência.

"Departamento de Biologia Vegetal, UFV, Viçosa, MG, Brasil.

IIIDepartamento de Fitotecnia, UFV, Viçosa, MG, Brasil. 
O murchamento precoce ocorre como resultado da perda prematura do turgor das células e pode ocorrer quando existe um desbalanço entre a absorção de água e a transpiração durante certo período de tempo, tendo como causa a alta taxa transpiratória ou a absorção de água limitada pela alta resistência hidráulica (VAN MEETEREN et al., 2001). O bloqueio vascular é relatado por muitos autores como a principal causa do desbalanço hídrico e posterior murchamento das flores (MAYAK et al., 1974; BLEEKSMA \& VAN DOORN, 2003), manifestando-se pela deposição de compostos orgânicos no lúmen dos vasos xilemáticos ou ainda pela exudação de látex (FINGER et al., 2003), pelo crescimento de microorganismos ou pela formação de bolhas de ar (VAN DOORN, 1997).

Vários compostos podem ser usados na solução de vaso para estender a longevidade da flor e cada um deles apresenta resultados diferenciados para cada espécie, não existindo um tratamento que promova ótimos resultados para todas as espécies (SACALIS, 1993). Quando adicionados na solução de vaso, estes podem reduzir a transpiração, elevar o potencial osmótico e fornecer energia para manter a homeostase celeular (VAN DOORN \& WOLTERING, 2008). A inclusão de compostos antimicrobianos, como 8-citrato de hidroxiquinolina (8-HQC), por exemplo, na solução de vaso, visa a reduzir a presença de bactérias e, como consequência, estender a longevidade floral (SACALIS, 1993). Em boca-de-leão, ICHIMURA \& HISAMATSU (1999) verificaram que a sacarose, em diferentes concentrações, promove a abertura da flor e aumenta a intensidade da coloração das pétalas.

Diversos trabalhos têm demonstrado o efeito benéfico da adição de produtos químicos conservantes nas soluções de manutenção das flores cortadas. Em boca-de-leão, a absorção da solução contendo 8-HQC por hastes cortadas é maior quando comparada com a absorção de água, demonstrando a eficiência desta em inibir o bloqueio vascular (MAROUSKY \& RAULSTON, 1970), e a vida de vaso pode ser aumentada com solução de vaso contendo 300mg L $\mathrm{m}^{-1}$ de 8 -HQC+1,5\% de sacarose (RAULSTON \& MAROUSKY, 1970).

A imersão da base das hastes em água quente é recomendada por alguns autores e, como efeito benéfico, mantém a qualidade das flores cortadas por reduzir a viscosidade da solução, facilitando a absorção e promovendo rápida recuperação da turgescência (VAN DOORN, 1997). Em hastes cortadas de boca-deleão, a utilização de água quente pode inibir o embolismo (SACALIS, 1993). A reidratação após o transporte e/ou armazenamento é recomendada para restaurar a turgidez das flores cortadas, saturando-as com água após passarem por um período de estresse hídrico (SUZUKI et al., 2001). Porém, com boca-de-leão, não há estudos sobre o comportamento da hidratação das hastes após o transporte ou armazenamento.

Este trabalho teve como objetivo avaliar o efeito de diferentes soluções conservantes e da reidratação com água quente na conservação póscolheita de inflorescências de boca-de-leão.

\section{MATERIAL E MÉTODOS}

Inflorescências de boca-de-leão, cultivar 'Potomac White', com seis a sete flores abertas na inflorescência (estágio de colheita comercial), foram colhidas de um campo de cultivo em Barbacena, Minas Gerais (MG), latitude: $21^{\circ} 13^{\prime} \mathrm{S}$, longitude: $43^{\circ} 46^{\prime} \mathrm{O}$ e altitude: $1164 \mathrm{~m}$ pela manhã (entre 7 e 8 horas). As hastes foram transportadas, a seco e sob temperatura ambiente, ao laboratório de análises por cerca de três horas, onde foram selecionadas e padronizadas com $70 \mathrm{~cm}$ de comprimento, sendo retiradas as folhas do terço final. Em seguida, foram distribuídas em vasos contendo 400mL das diferentes soluções avaliadas: (1) água desionizada $\left(20^{\circ} \mathrm{C}\right.$, tratamento controle), (2) água quente $\left(43^{\circ} \mathrm{C}\right)$ por uma hora e água desionizada $\left(20^{\circ} \mathrm{C}\right)$ colocada no vaso, (3) solução de Flower ${ }^{\circledR}$ (Ecoplanet, SC) que foi preparada seguindo as recomendações do fabricante $\left(20^{\circ} \mathrm{C}\right)$, (4) solução de vaso preparada com 200mg L $\mathrm{m}^{-1}$ de 8-HQC+20g L ${ }^{-1}$ sacarose+150 $\mathrm{mg} \mathrm{L}^{-1}$ ácido cítrico $\left(20^{\circ} \mathrm{C}\right)$, (5) água quente $\left(43^{\circ} \mathrm{C}\right)$ por uma hora e Flower ${ }^{\circledR}$ em solução de vaso $\left(20^{\circ} \mathrm{C}\right)$, e (6) água quente $\left(43^{\circ} \mathrm{C}\right)$ por uma hora e solução contendo $200 \mathrm{mg} \mathrm{L}^{-1} 8$ HQC, $20 \mathrm{~g} \mathrm{~L}^{-1}$ sacarose e $150 \mathrm{mg} \mathrm{L}^{-1}$ ácido cítrico $\left(20^{\circ} \mathrm{C}\right)$ como solução de vaso. Todas as hastes tiveram a base cortada (2cm) a cada 48 horas, no momento em que também foi feita a troca das soluções até o final da vida de vaso das inflorescências, quando apresentaram $50 \%$ ou mais das flores e/ou folhas murchas ou caídas (MACNISH et al., 2008).

A variação de massa fresca foi determinada por meio de pesagens das hastes antes de serem reidratadas (tempo 0), seis horas após estarem em cada solução e depois a cada 24 horas até o final da vida de vaso. Ao primeiro período analisado, foi atribuída uma massa inicial de $100 \%$. A variação de massa fresca foi expressa em percentual, em relação à massa fresca inicial, calculado pela fórmula $\Delta \mathrm{MF}(\%)=\left(\mathrm{MF}_{\mathrm{t}} / \mathrm{MF}_{\mathrm{t}-1}\right)$ / $\mathrm{MF}_{\mathrm{t}-1}$; em que $\mathrm{MF}_{\mathrm{t}}$ representa a massa fresca (g) da haste no tempo $\mathrm{T}=6,24,48 \mathrm{~h}$, etc., e $\mathrm{MF}$, a massa fresca da haste (g) no tempo anterior, desconsiderando a parte eliminada a cada 48 horas (HE et al., 2006). Após a colheita (tempo 0 ) e a cada 24 horas, foi obtido o número de flores abertas na inflorescência, até o final da vida de vaso das hastes. 
O teor relativo de água (TRA) das pétalas foi determinado antes da reidratação (tempo 0), seis horas após e a cada 24 horas até o final da vida de vaso das inflorescências, segundo o método descrito por CÁTSKY (1974), com modificações. As pétalas foram cortadas longitudinalmente e cada meia-flor representou uma unidade amostral; os cortes foram pesados para obtenção da massa fresca. Em seguida, foram depositados em espuma de poliuretano saturada com água, onde permaneceram até a completa saturação, cerca de cinco a seis horas, quando foi realizada uma nova pesagem para obtenção da massa túrgida. Posteriormente, os discos foram colocados em estufa, a $70^{\circ} \mathrm{C}$, por aproximadamente 48 horas, para obtenção da massa seca constante. O TRA foi calculado de acordo com a equação proposta por WEATHERLEY (1950): TRA=100 (MF - MS)/(MT - MS), em que MF, MS e MT representam respectivamente, em g, as massas fresca, seca e túrgida.

O delineamento experimental utilizado foi o inteiramente casualizado, com cinco repetições e duas hastes florais por unidade experimental, para análise da variação de massa fresca e contagem do número de flores abertas, e seis repetições, para análise do TRA. Os dados foram submetidos à análise de variância, e as médias foram comparadas pelo teste Tukey, em nível de 5\% de probabilidade, utilizando-se o Sistema para Análises Estatísticas (SAEG-UFV).

\section{RESULTADOS E DISCUSSÃO}

A vida de vaso das inflorescências de bocade-leão variou de três a sete dias e foi limitada pelo murchamento das flores e folhas, diferindo significativamente em resposta aos diferentes tratamentos (Tabela 1). A maior vida de vaso (sete dias) foi obtida em flores condicionadas em solução contendo 8-HQC, sacarose e ácido cítrico com ou sem a reidratação com água quente (Tabela 1), mostrando que a água quente não promoveu efeito positivo na longevidade. O efeito benéfico dos açúcares, como a sacarose, na senescência das flores de corte, deve-se ao fornecimento de substratos para a respiração; manutenção do balanço hídrico, redução da sensibilidade ao etileno e atraso na biossíntese autocatalítica desse gás (PUN \& ICHIMURA, 2003). Além disso, o aumento da longevidade pode estar associado à utilização do ácido cítrico, que controla o pH da solução (SACALIS, 1993), e ao 8-HQC, que inibe o crescimento de fungos, leveduras e bactérias (BRACKMANN et al., 2000), ambos controlando a oclusão vascular. O tratamento com 8-HQ, em crisântemos, conservou melhor as flores após a colheita
Tabela 1 - Vida de vaso das hastes cortadas de boca-de-leão submetidas a diferentes tratamentos.

\begin{tabular}{|c|c|}
\hline Tratamento & $\begin{array}{l}\text { Vida de vaso } \\
\text { (dias após } \\
\text { reidratação) }\end{array}$ \\
\hline Água desionizada (controle) & $3 \mathrm{C}$ \\
\hline Água quente & $3 \mathrm{C}$ \\
\hline Flower $^{\circledR}$ & $5 \mathrm{~B}$ \\
\hline 8-HQC+sacarose+ácido cítrico & $7 \mathrm{~A}$ \\
\hline Água quente $\rightarrow$ Flower $^{\circledR}$ & $5 \mathrm{~B}$ \\
\hline $\begin{array}{l}\text { Água quente } \rightarrow \text { 8- } \\
\text { HQC+sacarose+ácido cítrico }\end{array}$ & $7 \mathrm{~A}$ \\
\hline Média & 5 \\
\hline CV (\%) & - \\
\hline
\end{tabular}

Médias não seguidas por uma mesma letra diferem entre si pelo teste Tukey, a 5\% de probabilidade.

(BRACKMANN et al., 2000), com resultado semelhante ao obtido na espécie em estudo. A menor vida de vaso foi observada nas inflorescências mantidas em água desionizada, possivelmente por não ter controlado a oclusão vascular, nem ter fornecido substrato para os processos bioquímicos que ocorrem após a colheita. Em A. majus 'Potomac Pink', a solução contendo $10 \mu \mathrm{L}$ $\mathrm{L}^{-1}$ de dióxido de cloro $\left(\mathrm{ClO}_{2}\right)$ prolongou a vida de vaso das inflorescências, mostrando que o controle da oclusão vascular tem resultados positivos no aumento da longevidade floral (MACNISH et al., 2008).

As hastes mantidas em solução contendo 8-HQC, sacarose e ácido cítrico tiveram aumento na massa fresca superior aos demais tratamentos a partir de 24 horas (Figura 1), apresentando ganho de massa de até $24 \%$ durante o período avaliado, enquanto hastes mantidas em Flower ${ }^{\circledR}$ apresentaram ganho máximo de 5\%. De acordo com SACALIS (1993), o composto de 8HQC inibe o crescimento bacteriano, podendo reduzir a oclusão vascular e aumentar a absorção da solução pelas hastes, o que pode ter ocorrido neste trabalho, de acordo com os resultados do aumento de massa fresca. Semelhantemente, a absorção da solução de 8HQC por hastes cortadas de boca-de-leão 'Pan American Summer Pink’ foi maior quando comparada com a absorção de água, comprovando a eficiência dessa solução (MAROUSKY \& RAULSTON, 1970).

A reidratação com água quente não foi eficiente em prolongar a longevidade das inflorescências de boca-de-leão, visto que foi observada, semelhantemente ao tratamento controle, acentuada queda na massa fresca entre 24 e 48 horas (Figura 1). Após 72 horas, as hastes reidratadas com água quente e, posteriormente mantidas em água desionizada, apresentaram $50 \%$ ou mais das pétalas e/ 


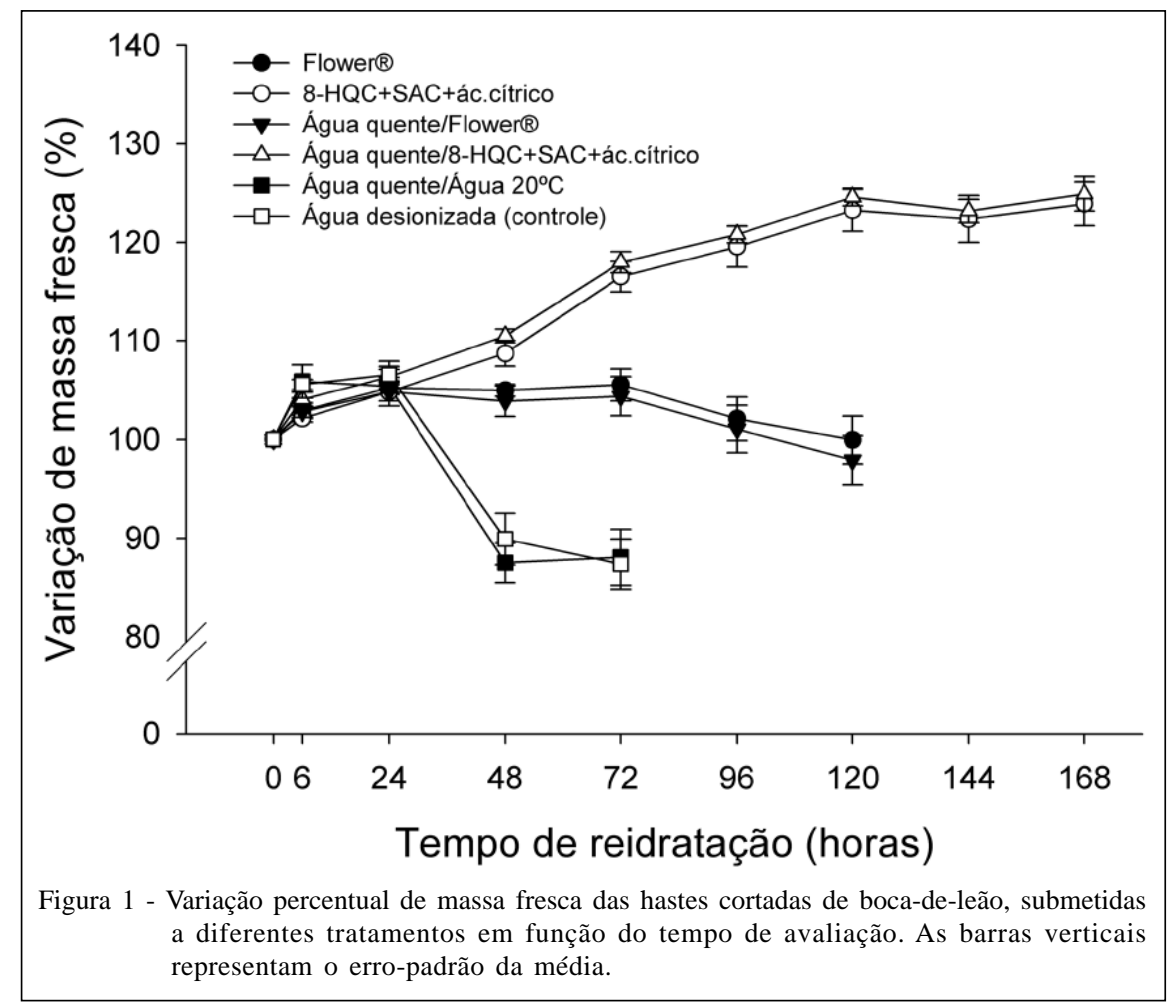

ou folhas murchas. Em rosas, LEONARD et al. (2001) mostraram que o uso de água $43^{\circ} \mathrm{C}$, por uma hora, tem efeito benéfico somente no aumento da abertura da flor, não mostrando melhoria da qualidade e/ou aumento da longevidade.
O TRA das pétalas das hastes condicionadas em Flower ${ }^{\circledR}$ ou solução contendo 8HQC, sacarose e ácido cítrico foi superior em comparação ao TRA das pétalas mantidas em água desionizada (Figura 2), comprovando a maior eficiência

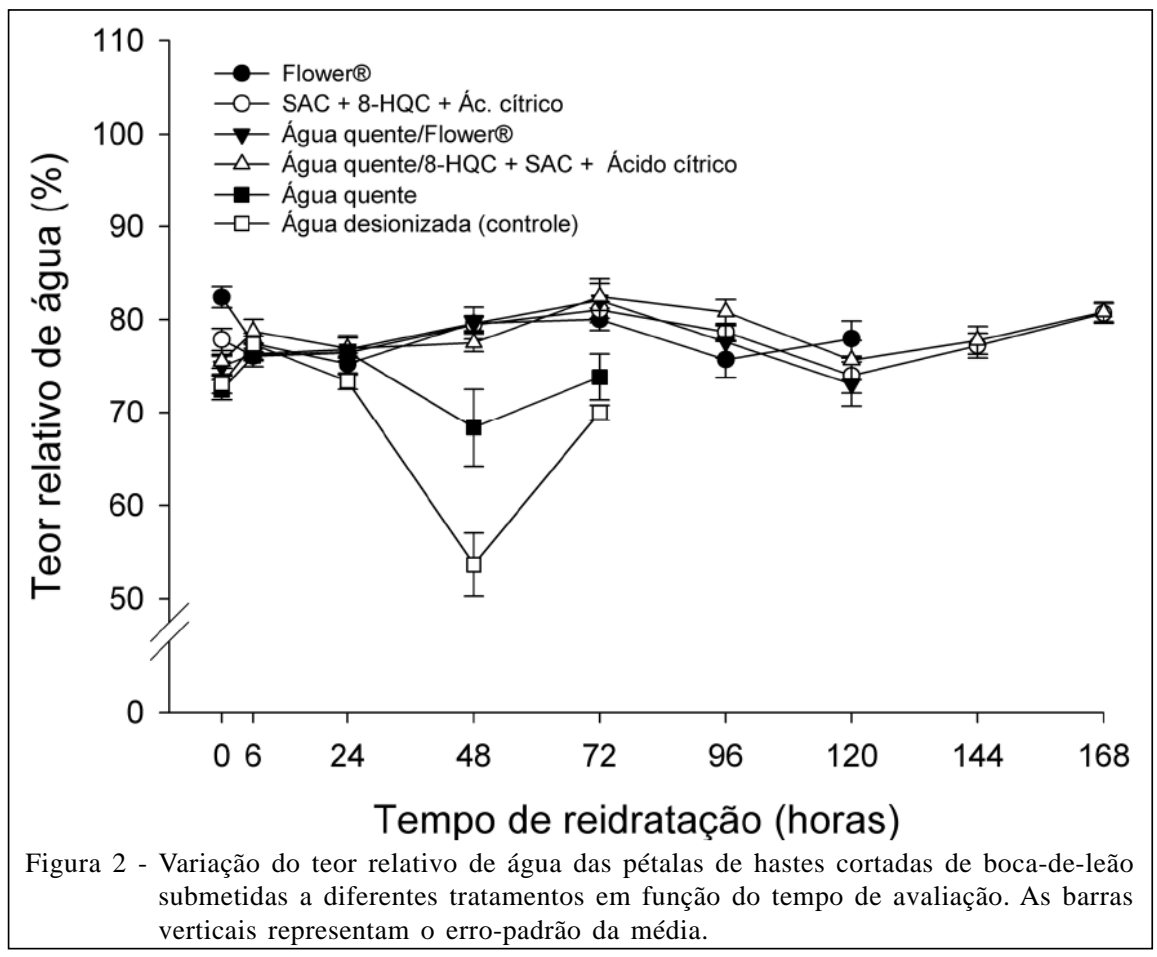

Ciência Rural, v.40, n.4, abr, 2010. 
das soluções de vaso na capacidade de reidratação das inflorescências. A maior turgidez das pétalas se deu às 72 horas, quando o TRA atingiu cerca de $80 \%$. Entre 24 e 48 horas, observou-se uma queda acentuada no TRA das pétalas das hastes mantidas em água desionizada, o que, possivelmente, determinou o fim da vida de vaso.

O corte da base da haste após 48 horas do início da reidratação propiciou aumento do TRA das pétalas principalmente nas hastes mantidas em água desionizada (Figura 2), sugerindo uma possível oclusão vascular nessas hastes e evidenciando que a curta vida de vaso das inflorescências de boca-de-leão está relacionada ao desequilíbrio hídrico. Inflorescências de Zinnia elegans que receberam o corte na base da haste a cada 12 horas apresentaram um leve aumento de massa fresca até 44 horas após a colheita e maior longevidade, sendo considerado, portanto, efetivo na melhoria de hidratação das flores (CARNEIRO et al., 2002).

O número de flores abertas não diferiu entre os tratamentos (Tabela 2), entretanto aumentou ao longo do período de avaliação e não foi observada abscisão de flores, mostrando a eficiência dos tratamentos em não inibir a abertura floral. Resultados semelhantes foram obtidos por LARSEN \& SCHOLES (1966), que mostraram o efeito significativo do composto 8-hidroxiquinolina no número de flores abertas e na vida de vaso de hastes cortadas de bocade-leão das cultivares ‘Snowman', 'Jackpot', 'Barbara', 'Golden Spike’ e 'White Rocket'. Em crisântemos,
BRACKMANN et al. (2000) mostraram que a solução de sacarose foi a que facilitou a abertura dos botões, por ser uma fonte de energia para a respiração e outros processos metabólicos.

Contudo, o condicionamento das hastes cortadas de boca-de-leão em soluções de vaso como o Flower ${ }^{\circledR}$ e o 8-HQC, sacarose e ácido cítrico mostrouse eficiente para prolongar a vida de vaso e manter a qualidade das flores possivelmente por inibir a oclusão vascular e manter o equilíbrio hídrico das inflorescências.

\section{CONCLUSÕES}

A vida de vaso das inflorescências de bocade-leão pode ser aumentada com a utilização de soluções de vaso eficientes, e a solução contendo 200mg L ${ }^{-1}$ de 8-HQC, 20g L $\mathrm{L}^{-1}$ de sacarose e $150 \mathrm{mg} \mathrm{L}^{-1}$ de ácido cítrico foi a que propiciou maior longevidade às hastes.

O corte periódico na base da haste promove aumento na absorção da solução ou água de vaso, mostrando eficiência na manutenção da hidratação das flores.

\section{AGRADECIMENTOS}

À Coordenação de Aperfeiçoamento de Pessoal de Nível Superior (Capes) a ao Conselho Nacional de Desenvolvimento Científico e Tecnológico (CNPq), pela concessão de bolsa aos autores Luciana Marques Vieira e Fernando Luiz Finger, respectivamente.

Tabela 2 - Número de flores abertas na inflorescência de boca-de-leão submetidas a diferentes tratamentos em função do tempo de avaliação.

\begin{tabular}{|c|c|c|c|c|c|c|c|c|}
\hline \multirow{2}{*}{ Tratamento } & \multicolumn{8}{|c|}{ 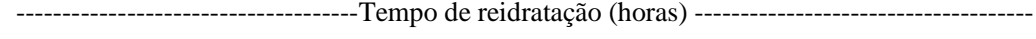 } \\
\hline & 0 & 24 & 48 & 72 & 96 & 120 & 144 & 168 \\
\hline Água desionizada (controle) & $10,7 \mathrm{~A}$ & $11,9 \mathrm{~A}$ & $14,4 \mathrm{~A}$ & $17,6 \mathrm{~A}$ & - & - & - & - \\
\hline Água quente & $10,5 \mathrm{~A}$ & $12,0 \mathrm{~A}$ & $14,4 \mathrm{~A}$ & $17,0 \mathrm{~A}$ & - & - & - & - \\
\hline Flower $^{\circledR}$ & $10,0 \mathrm{~A}$ & $11,5 \mathrm{~A}$ & $14,6 \mathrm{~A}$ & $17,3 \mathrm{~A}$ & $19,9 \mathrm{~A}$ & $21,7 \mathrm{~A}$ & - & - \\
\hline 8-HQC+SAC+ ac.cítrico & $9,1 \mathrm{~A}$ & $10,9 \mathrm{~A}$ & $14,7 \mathrm{~A}$ & $17,2 \mathrm{~A}$ & $19,2 \mathrm{~A}$ & $21,4 \mathrm{~A}$ & $23,1 \mathrm{~A}$ & $24,4 \mathrm{~A}$ \\
\hline Água quente/ Flower ${ }^{\circledR}$ & 9,9 A & $11,4 \mathrm{~A}$ & $14,2 \mathrm{~A}$ & $16,7 \mathrm{~A}$ & $17,9 \mathrm{~A}$ & $20,0 \mathrm{~A}$ & - & - \\
\hline Água quente/8-HQC+SAC+ ac.cítrico & $9,5 \mathrm{~A}$ & $10,6 \mathrm{~A}$ & $14,6 \mathrm{~A}$ & $17,2 \mathrm{~A}$ & $19,2 \mathrm{~A}$ & $21,2 \mathrm{~A}$ & $22,2 \mathrm{~A}$ & $23,7 \mathrm{~A}$ \\
\hline Média & 9,95 & 11,4 & 14,5 & 17,2 & 19,0 & 21,0 & 22,6 & 24,0 \\
\hline CV (\%) & 10,1 & 8,4 & 8,5 & 7,2 & 7,7 & 6,9 & 6,7 & 11,2 \\
\hline
\end{tabular}

Médias não seguidas pela mesma letra, na coluna, diferem entre si pelo teste Tukey, a 5\% de probabilidade. 


\section{REFERÊNCIAS}

BLEEKSMA, H.C.; VAN DOORN, W.G. Embolism in rode stems as a result of vascular occlusion by bacteria. Postharvest Biology and Technology, v.29, p.334-340, 2003. Disponível em: <http:/ /dx.doi.org/10.1016/S0925-5214(03)00049-8>. Acesso em: 10 nov. 2009. doi: 10.1016/S0925-5214(03)00049-8.

BRACKMANN, A. et al. Armazenamento de crisântemos Dedranthema grandiflora cv. red refocus em diferentes temperaturas e soluções conservantes. Revista Brasileira de Agrociência, v.6, n.1, p.19-23, 2000. Disponível em: <http:/ /www.ufpel.tche.br/faem/agrociencia>. Acesso em: 20 jan. 2010.

CARNEIRO, T.F. et al. Influência da sacarose e do corte da base da haste na longevidade de inflorescências de Zinnia elegans. Pesquisa Agropecuária Brasileira, v.37, n.8, p.1065-1070, 2002. Disponível em: <http://www.scielo.br/pdf/pab/v37n8/ 11665.pdf $>$. Acesso em: 20 jan. 2010.

CÀTSKY, J. Water content. In: SLAVIK, B. Methods of studying plant water relations. Berlin: Springer-Verlag, 1974. p.121-131.

FINGER, F.L. et al. Colheita, classificação e armazenamento de inflorescências. In: BARBOSA, J.G. Crisântemos. Viçosa: Aprenda Fácil, 2003. Cap. 7, p.123-140.

HE, S. et al. Stem end blockage in cut Grevillea 'Crimson Yullo' inflorescences. Postharvest Biology and Technology, v.41, p.78-84, 2006. Disponível em: <http://dx.doi.org/ 10.1016/j.postharvbio.2006.03.002>. Acesso em: 08 nov. 2009. doi: 10.1016/j.postharvbio.2006.03.002.

ICHIMURA, K.; HISAMATSU, T. Effects of continuous treatment with sucrose on vase life, soluble carbohydrate concentrations, and ethylene production of cut snapdragon flowers. Journal of the Japanese Society of Horticultural Science, v.68, p.61-66, 1999. Disponível em: <http:// rms1.agsearch.agropedia.affrc.go.jp/contents/JASI/pdf/society/ 58-1864.pdf>. Acesso em: 12 nov. 2009.

LARSEN, F.E.; SCHOLES, J.F. Effects of 8-hydroxiquinoline citrate, Ndimethyl amino succinamic acid , and sucrose on vaselife and spike characteristics of cut snapdragons. Journal of the American Society for Horticultural Science, v.89, p.694-700, 1966.

LEONARD, R.T. et al. Evaluation of long term transport of Colombian grown cut roses. Acta Horticulturae, v.543, p.293297, 2001.

MACNISH, A.J. et al. Treatment with clorine dioxide extends the vase life of selected cut flowers. Postharvest Biology and Technology v.50, p.197-207, 2008. Disponível em: <http://dx.doi.org/10.1016/j.postharvbio.2008.04.008>. Acesso em: 10 nov. 2009. doi: 10.1016/ j.postharvbio.2008.04.008.

MAROUSKY, F.J.; RAULSTON, J.C. Interaction of flower preservative components and light on fresh weight and longevity of snapdragon cut flowers. Proceedings of the Florida State Horticultural Society, v.83, p.445-448, 1970.

MAYAK, S. et al. The water balance of cut rose flowers. Physiologia Plantarum, v.31, p.15-22, 1974.

PUN, U.K.; ICHIMURA, K. Role of sugars in senescence and biosynthesis of ethylene in cut flowers. Japan Agricultural Research Quarterly, v.37, p.219-224, 2003. Disponível em: <http://www.jircas.affrc.go.jp/english/publication/jarq/37-4/ 37-04-02.pdf>. Acesso em: 10 nov. 2009.

RASLSTON, J.C.; MAROUSKY, F.J. Effects of 8-10 day $5^{\circ} \mathrm{C}$ storage and floral preservatives on snapdragon cut flowers. Proceeding of the Florida State Horticultural Society, v.83, p. 415-419, 1970.

SACALIS, J.N. Cut flowers: prolonging freshness. 2.ed. Batavia: Ball Publishing, 1993. 110p.

SAEG - Sistema para Análises Estatísticas, Versão 9.1: Fundação Arthur Bernardes. Viçosa: UFV, 2007. Disponível em: <http://www.ufv.br/saeg/download.htm>. Acesso em: 15 jul. 2009.

SUZUKI, A. et al. Effects of retail hydration on water uptake and quality of 'Madame Delbard” roses after long term transport. Acta Horticulturae, v.543, p.251-256, 2001. Disponível em: <http://www.actahort.org/books/543/543_30.htm>. Acesso em: 12 nov. 2009.

VAN DOORN, W.G. Water relations of cut flowers. Horticultural Reviews, v.18, p.1-85, 1997.

VAN DOORN, W.G.; WOLTERING, E.J. Physiology and molecular biology of petal senescence. Journal of Experimental Botany, v.59, n.3, p.453-480, 2008. Disponível em: <http://jxb.oxfordjournals.org/cgi/reprint/59/3/ 453>. Acesso em: 12 nov. 2009. doi:10.1093/jxb/erm356.

VAN MEETEREN, U. et al. Processes and xylem anatomical properties involved in rehydration dynamics of cut flowers. Acta Horticulturae, v.543, p.207-213, 2001. Disponível em: <http://www.actahort.org/books/543/543_25.htm>. Acesso em: 11 nov. 2009.

WEATHERLEY, P.E. Studies in water relations of cotton plant. In: The field measurament of water deficits in leaves. New Phytology, v.49, p.81-97, 1950. 